An educators' perspective on reflexive pedagogy: identity undoing and issues of power

\author{
Marian Iszatt-White \\ Lancaster University Management School
}

\author{
Steve Kempster \\ Lancaster University Management School \\ and \\ Brigid Carroll \\ University of Auckland
}

Corresponding author:

Marian Iszatt-White

Department of Leadership and Management

Lancaster University Management School

Lancaster, LA1 4XY

m.iszattwhite@1ancaster.ac.uk 


\title{
An educators' perspective on reflexive pedagogy: identity undoing and issues of power
}

\begin{abstract}
This article looks at reflexive pedagogical practice and the 'identity undoing' that such practice demands from educators. Such identity undoing is found to have strong connections to the impact on identity of power relations, resistance and struggle. A dialogic 'testimonio' approach is adopted tracing two of the authors' experiences of attempting to introduce a reflexive pedagogy within a structured, accredited learning intervention. This approach analyses educators' own reflexive dialogue to make visible the assumptions and tensions that are provoked between educators and students in a reflexively orientated learning process. In undertaking this analysis, we problematize the pursuit of a reflexive pedagogical practice within executive and postgraduate education and offer a paradox: the desire to engage students in reflexive learning interventions - and in particular to disrupt the power asymmetries and hierarchical dependencies of more traditional educator-student relationships - can in practice have the effect of highlighting those very asymmetries and dependencies. Successful resolution of such a paradox becomes dependent on the capacity of educators to undo their own reliance on and even desire for authority underpinned by a sense of theorybased expertise.
\end{abstract}

Key words: reflexive dialogue; reflexive pedagogy; power; identity undoing; leadership development; educator 


\section{Introduction}

It is a continuing criticism of critical management studies within education (Collinson and Tourish, 2015; Ford and Harding, 2007) that it fails to turn a critical lens upon itself and address the power asymmetry between educators and students. This could be considered especially salient when implementing a pedagogy centred on reflexive dialogue, as is the context catalysing this inquiry. Current thinking on reflexive pedagogy has sought to recast the tutors' power away from that of an instructor delivering expertise, to educator-asfacilitator in which power shifts in the relationship towards the students (Hibbert, 2013). Such a shift is generally seen as desirable (Hibbert and Cunliffe, 2015) but we problematize how desirable this is for educators by asking what identity issues are raised for academics coming to terms with the revised (and potentially diminished) sense of identity occasioned by this approach. The need to understand the element of 'identity undoing' (Nicholson and Carroll, 2013) which occurs for academics in this context is at least as important as - and inevitably related to - the issues of power already raised above.

Taking Hibbert's (2013) study of the implications of reflexive pedagogy from the students' perspective as a jumping-off point, we seek to explicate the parallel experiences of such pedagogy for the educators. In drawing attention to the educators' experience, we respond to an important facet of the recent calls for a greater critical understanding of the 'subjective experience, tensions and outcomes' (Gagnon and Collinson, 2014: 664) of leadership development programmes (LDPs), and in particular the inextricability of power and identity. We draw attention to the way in which the educator/facilitator's experience is 'dislodged from an implicit position of mastery' (Hibbert and Cunliffe, 2015: 186) by the adoption of a reflexive pedagogy - what Ellsworth (1989, cited in Hibbert and Cunliffe, 
2015: 186) calls 'a pedagogy of the unknowable in which we can never fully know ourselves, our experience, others, nor the impact of our actions'.

This then is our project. We turn the reflexive lens on ourselves and our experience of adopting a reflexive pedagogy on an accredited LDP. Specifically, we explore the disruption and challenge to our taken-for-granted sense of identity and power within the studenteducator relationship. The article is structured as follows. We begin by examining the notion of identity undoing in the context of LDPs, particularly as occasioned by the juxtaposition of power relations and resistance. Next, we outline a dialogic 'testimonio' approach whereby we use vignettes drawn from our own reflexive dialogue - a series of letters written between two of the authors - as a process of inquiry into reflexive pedagogy from the educator's perspective. We use a detailed analysis of these vignettes to unpack the issues of educator identity undoing and power/resistance in the context of a reflexive pedagogy. We conclude by discussing the presence of a paradox within reflexive education that the greater the success in enabling reflexive dialogue between students, the greater the desire of the educator to intervene to limit the scope and impact of reflexivity in order to not become 'a spare part'.

\section{Reflexive Pedagogy}

Reflexivity - notably described as the sine qua non of critical management studies (Fulop, 2002) - is as fundamental to the learning that can be gleaned from surfacing our own implicit knowing as it is to the emancipatory agenda surrounding issues of power. Drawing from the language of ethnomethodology, reflexive dialogue is a vehicle for considering the 'ongoing accomplishment of organized artful practices of everyday life' (Garfinkel, 1967: 10) such that we know better 'how to go on' (Wittgenstein, 1953: 59). Key to reflexivity is its inherent recursiveness in 'translat[ing] something [i.e. taken-for-granted norms and assumptions] from being used for thinking to being that which we think about' (Hibbert, 2013: 805). What occurs 
in reflexivity is not the 'outside in' (Baker and Kolb, 1993) reflective learning of 'theoretical insights or major intellectual breakthroughs, but moments in which we [...] "understand something that is already in plain view" (Wittgenstein, 1953: 89) and the difference this new understanding may make to our lives' (Cunliffe, 2002: 57).

These two key elements of the emancipatory agenda, power and reflexivity, may not work in concert however. Processes of reflexivity can bring about disturbance and disruption and power may be exercised to limit this disturbance. The discomfort encountered is the 'disruptive' (Hibbert et al., 2010: 55) forerunner to the 'clearing out' or 'unlearning' (Antonacopoulou, 2009: 422) of existing knowledge and the questioning of assumptions and perceptions to make room for new insights. In exploring these tensions, the lens of research on reflexive dialogue has focused understandably on recipients of pedagogic designs and on the 'liminal space or state of between-ness' (Hawkins and Edwards, 2015: 24) occupied by students as they engage with these tensions and transition from one identity to another in the course of leadership learning. Here we shall reverse the lens, and look at the impact of the pedagogy of reflexive dialogue on us, the designers and educators, to explore impacts of being disruptive, creating 'sticky-moments' (Riach, 2009: 361), and generating discomfort associated with the taken-for-granted aspects of identity as teacher and the use of power in learning. We therefore ask the question, if in the educator's context such disruption can be resisted and the pedagogy be manipulated, might this occur? Would this paradoxically limit the emancipatory potential of a reflexive pedagogy? Would indeed an educator use power to resist identity undoing?

\section{Identity and 'identity undoing' in the context of leadership education}

Identity is a well-established construct in critical management studies (see Brown, 2001; Brown and Lewis, 2011; Collinson, 2003; Thomas, 2009), is becoming so in critical 
leadership studies (Carroll and Levy, 2010; Ford, 2006) and is starting to be adopted in critically orientated leadership development work (Carroll and Levy, 2010; Gagnon, 2008; Gagnon and Collinson, 2014). Such studies tend to build on Alvesson and Wilmott's (2002) 'identity work' framework revolving around an interplay between self-identity (the self as reflexively understood), identity work (the ongoing struggle to achieve or accomplish selfidentity) and identity regulation (the - often tacit - adoption of discourses and practices that shape certain identities above others). This framework speaks strongly to the locating of identity within broader organisational themes of power, control and discipline where the subject's 'self-definition(s), coherence(s) and meaning(s)' (Alvesson and Wilmott, 2002: 622) are targeted and moulded in multiple points of intersection with an organisation. The result is that 'people are continuously engaged in forming, repairing, maintaining, strengthening or revising, the constructions that are productive of a precarious sense of coherence and distinctiveness' (Alvesson and Wilmott 2002: 626).

That leadership development requires participants to engage in the dynamics of identity work and identity regulation is becoming better understood (Carden and Callahan, 2007; Carroll and Levy, 2010; Gagnon, 2008; Gagnon and Collinson, 2014). Such development cannot avoid the presence of implicit - and frequently explicit - leadership models and judgements about what counts (or not) as leadership that participants have to contend with and work through in what has been called an 'identity workspace' (Petriglieri, 2011). That educators and facilitators also engage in identity work in the same identity workspace is however a very recent field of scholarly interest and one to which we seek to contribute.

Nicholson and Carroll's (2013) work on identity undoing provides a powerful conceptualisation of identity struggle that seems most resonant with the tensions experienced 
by educators in reflexive pedagogical practice. They theorise, beyond the traditional foci of identity formation, construction and regulation, to what they contend has been an overlooked phenomenon of loss, fragmentation, and disruption which they term identity undoing. Identity undoing is presented as 'kaleidoscopic' (Nicholson and Carroll 2013: 1230) and manifested through a range of processes from reflexive critique (shaking up) to unlearning (letting go), to episodes of 'stuckness' and seeming immobility (floundering), accompanied by a similar range of emotional responses from delight to pain. While the focus of Nicholson and Carroll's (2013) work is primarily on the participants of a leadership development programme, their gaze inevitably includes facilitators/educators. In the early interaction data from their study facilitators are generally analysed as hierarchical figures with the institutional and pedagogical power to inflict, invite, sanction and moderate identity undoing. In the subsequent analysis of facilitator interviews, facilitators reveal their own struggles with identity and accompanying anxiety and discomfort with holding authority in processes which depend on participants feeling agentic. The insight that 'facilitators too can be subjects and objects in identity processes and that understanding one's impact as facilitator could be assisted by seeing oneself as an object' (2013: 1241) seems profound and ripe for further exploration.

\section{Power and resistance as shapers of educator identity}

It is some years since Reynolds (1999) made ' $[\mathrm{t}]$ he case for rehabilitating less hierarchical approaches to learning'. He hoped to 'achieve a coherence of values between educational content and process' and 'avoid the contradiction between a critically based curriculum and a methodology that reinforces authoritarian relationships' (1999: 550). More recently, Nicholson and Carroll (2013: 1242) note the 'power and authority implicit in facilitators' expertise' and the evident asymmetry felt by their research participants/students even in a 
more facilitative, less didactic learning environment. The 'judgmental gaze' (Ford, Harding and Learmonth, 2010: s75) continued to be personified by the course director and internalized by students through the theories presented, the assessment of outputs and the adoption of prescribed managerial discourses. Thus LDPs - and particularly, perhaps such high-profile, assessed programmes as Executive MBAs - remain 'technologies of power' (Nicholson and Carroll, 2013: 1227) which shape and dictate the ways in which participants seek to craft and reinvent themselves.

That, of course, is not to argue that students do not resist such technologies of power, as indeed they do. Gagnon and Collinson (2014) argue that leadership development is intrinsically identity-shaping and must be considered as having power-effects, yet within that there are always 'opportunities for oppositional discursive practices and resistance' (2014: 4). In their study of two global LDPs they investigate what they call 'identity-targeting practices' (2014: 5) where certain 'idealized' (2014: 9) identities of leaders are detailed, emphasised and even imposed on participants. While their focus is largely on the anxiety and compliance with which such identity-targeting practices were received, they also note 'surprising levels of dissent and opposition' (2014: 16) with participants making choices to enact alternative and oppositional identities instead of the idealized ones on offer. In the extreme, participants were even observed as choosing to exit the programme. Carroll and Nicholson (2014) likewise argue that leadership development spaces are 'steeped in power, resistance and struggle' but go further to argue these 'entangle facilitators and participants alike' (2014: 1414). They propose a more generative and fluid understanding of 'resisting work' which they argue needs to be understood as a set of relational and situated practices intimately engaged with the exercise of power and leadership. They reason that a binary logic that separates out power and resistance as belonging to separate groups is simplistic. This said, whilst their article goes on to explore how the facilitators/educators 'consent, cope and resist' 
(Kondo, 1990: 224) with and in relation to participants, it doesn't take the additional step of exploring the parallel issue of educator tensions and struggles with power and identity.

The ability of educators to radically alter or reduce power imbalances in such programmes may be partial at best. In major part this is a consequence of the 'social, psychological and cultural attributes of the training room' and the performative nature of the 'ritual, scripted and ceremonial behaviours' (Ford and Harding, 2007: 481) which occur there. Inevitably it is most pronounced where assessment is a central aspect of the learning context. So despite much canvassing (see for example Ford and Harding, 2007; Frank, 2005) the potential for learning interventions which redress the tutor-student power imbalance may be much more problematic than anticipated, with particular attention needing to be paid to the educator's perspective.

\section{Our experimental crucible}

The context for this study was a leadership module within an Executive MBA in the home institution of two of the authors. The cohort consisted of 16 post-experience students from four nationalities and seven sectors. The stated objective was 'to provide a framework within which leadership knowledge and experience can be explored and articulated, in order to gain a deeper and more grounded understanding of individual leadership practice and of leadership practice generally' ([reference withheld for review purposes]).

Drawing on Kempster and Iszatt-White (2013) the designed pedagogy was to place the student/managers into pairs to become co-coaching discussants. The focus of the pair was to help each other examine past influences on their own leadership development/practice and/or current leadership challenges in their working contexts. Each discussant was to interrogate their partner's challenge drawing on relevant theory to enable a critically reflective dialogue. It was a transparent aspect of the module (as set out in the module outline 
document) that the culmination of the co-coaching process would be a credit-bearing written assessment.

Both [first author] and [second author] were involved throughout the module in supporting the co-coaching process, providing clarity as to the aims and assessment format and as additional tutor support to the co-coaching pairs. Time was given at each of the 10 programme modules for a formal input on leadership and for the co-coaching pairs to meet. The participants were encouraged to capture on-going insights and reflections on the cocoaching discussions in a learning journal. The assignments produced at the end of the module, together with the learning journals, formed part of the resource material we drew upon in this research.

\section{Research approach: reflexive dialogue through an exchange of letters}

The research approach consisted of two phases: the first involved the writing and exchanging of letters and the second related to the analysis of these letters. Using letters helped us become reflexive authors (McAdams and Cox, 2010) and make salient the contextual features shaping our experience. Connelly and Clandinin (1990: 6) suggest that '[1]etter writing [is] a way of engaging in written dialogue ... [as] a way of offering and responding to tentative narrative interpretations.' In the letters, which constitute the 'data' for this paper, the two first authors draw on a range of resources: memos and emails between themselves and with the students; interviews with the students exploring their experiences of the educational process; the students' reflective assignments and learning journals; and scribbled notes from the authors' ad-hoc corridor conversations and meetings. The process of writing letters was used as a method of inquiry in itself (Richardson, 2000). The letters form a testimonial narrative or 'testimonio' that is 'produced in the first person by a narrator who is also the real protagonist or witness of the events she or he recounts' (Beverley, 2000: 555). In this 
testimonio conversation two of the authors, as joint protagonists, provide witness to each other, 'retelling' as well as 'reliving' the events and emotions each experienced (Connelly and Clandinin, 1990: 4). The letters thus form a constructed semblance of impressions, hunches, feelings and emotions that become organised in a series of arguments as to what each of us understood, to reveal 'narrative secrets' (Kermode, 1981) which might otherwise not have been surfaced. The letters illuminate other relevant aspects of our lives (Clandinin and Connelly, 2000) namely our individual aspirations and ethics of teaching and educating, a sense of identification with aligned practices, and aspects of power as institutionally embedded in the tutor/academic role. Prior to writing the letters we were not clear what we had experienced in a theoretical sense. Rather, we expressed tacit and felt notions of struggle, loss and resistance. Theorising of these notions emerged as the letters were written and exchanged. The first was written by [first author] and set out what our research originally sought to explore and the surprising issues we encountered. The second letter by [second author] responded to these issues by reflecting on the ideas presented and offering a series of alternative interpretations. In the final letter, [first author] responded by drawing on previous personal experience of facilitating learning within an experiential educational trust to explore an emerging argument from [second author's] letter.

Having captured the ebb and flow of our emerging understanding, the second phase sought to focus on what had emerged as the key elements of our shared experiences. Of prominence were aspects of educator identity, power and resistance in the context of a reflexive pedagogy. These were the salient impressions of the letter authors, but this was a co-constructed sense making: how might these letters be interpreted from an independent perspective? This then was the role of our third author. [third author] not only offered an independent eye and a robust process of analysis with regard to our testimonio data, but also stimulated a second order reflexivity. [third author] forensically examined the testimonio 
data, extracting sentences and words and offering up nuanced interpretations. In response, the letter authors contextualised such interpretations to stay close to the meaning the events/experiences held for us, the 'actors'. The iterative dialogue provided a useful trail of evidence and reasoning to establish the authenticity and credibility of our interpretation (Denzin and Lincoln, 2000). To this end, [third author] undertook a 'careful reading and rereading' (Rice and Ezzy, 1999: 258) of the testimonio letters, from which she drew a list of vignettes which best illustrated the emergent themes of identity-undoing and issues of power/resistance. The use of longer vignettes was considered desirable to retain the richness and intensity of the original letters: to sustain a sense of verisimilitude to the original reflexive account whilst at the same time being cognisant of the need to avoid becoming 'lost in minutia' by 'always [having] a sense of the whole' (Connelly and Clandinin, 1990: 7). Drawing on Fereday and Muir-Cochrane (2006), it was noted that the importance of a theme could be established by a single comment rather than requiring repetition where this comment had sufficient resonance. Thus the process 'involved recognizing (seeing) an important moment and encoding it (seeing it as something)' prior to a process of interpretation' (Boyatzis, 1998, cited in Fereday and Muir-Cochrane, 2006: 83). The final stage of our iterative dialogue centred around the process of review and re-review to clarify the relationship of the themes with the vignettes, and subsequently with our theorising about the impact of a reflexive pedagogy on the educators with regard to identity undoing, resistance and power.

\section{Talking about reflexive pedagogy in an MBA leadership learning intervention}

\section{Letter 1 - [first author] to [second author]}

The visceral experience of disappointed hopes: It was ... interesting (and a bit disappointing to be honest after the efforts we put in to this) to see the different ways in which participants 
talked about the role of theory. Theory seemed to operate as a shared language for naming/articulating ideas about leadership practicelexperience, but it didn't seem to be the driving force behind participant learning: Adam T commented that he and his partner 'dipped into theory a little bit initially', but then later 'the majority of our conversation ... was based on more practical issues and just more storytelling rather than anything else.' Richard made a similar point about how he worked with his partner, saying: 'We don't seem to be driving with the theory. We seem to be driving with the situation and then at a later point we'll say "ah, that sounds like it's this type of leadership".'

This first vignette comes after an acknowledgement by [first author] of the assumptions she and [second author] had made about the leadership learning intervention they had introduced in terms of its benefits for students and the role of theory in supporting the delivery of in-depth practical learning. Implicit in this is the value assumed to be derived from theory and hence the 'expert' identity of the educators as those who delivered the theory. [First author] had also expressed the hopes they both had for the creation of 'more equal power relations' and student engagement with and ownership of their learning. After this optimistic start, the vignette conveys an emotional quality through the use of phrases like 'a bit disappointing' alongside 'interesting' - and speaks to the truth of Hibbert and Cunliffe's (2015: 186) statement that we 'need [to make] space for [our] own emotional experiences'. The 'a bit disappointing' refers to the considerable effort put in by the educators to highlight the worth of theory only to find it tended to be used in a categorizing manner ("shared language for naming/ articulating ideas", "ah, that sounds like it's this type of leadership"). It also speaks, perhaps, to the unease felt by the author in relation to her role as an educator in the wake of adopting a reflexive learning intervention. As the letter continues, these observations take on the character of a precursor to the personal implications for the author of this 'devaluing' of theory. 
Identity undoing: So much for what is happening for the students and what they are experiencing! What about us? In designing the module I-and, I think, we - didn't really think about how the adoption of a reflexive pedagogy might feel. In this regard, I am now starting to become aware of my own feelings in relation to working with a reflexive pedagogy and, in particular, my sense of a loss of identity. I hadn't realised how much we traditionally present ourselves as 'masters of theory', and how embracing a pedagogy in which emergence and becoming are central aspects-would raise uncomfortable power and identity issues for ourselves. Our traditional 'sage on the stage' identity gives way to the 'guide on the side' (King, 1993) within such a reflexive pedagogy and it is hard not to feel somewhat insecure about what our contribution is/should be in this context.

In what emerges as a recurrent theme in the testimonio letters, and in particular within this vignette, [first author] acknowledges a form of identity undoing happening to her - one which the educators, possibly unwittingly, have done to themselves. Given theory has become something to be 'dipped into' as opposed to 'driving' with, then the role of 'master of theory' appears redundant and that is experienced as 'felt...loss'. Feeling pedagogical choices, as opposed to designing them, appears gradual, relational, situated and visceral. For [first author] it feels 'uncomfortable' and 'insecure' to be unanchored by theory. Remember though that theory hasn't been rejected but repositioned by participants. To that end we need to register that theory is associated with 'traditional' 'sage on the stage' educator approaches and not with more facilitative 'guide on the side' alternatives. We will come back to this series of associations but for now we might ask the question why educators still couldn't be masters of theory alongside 'guides on the side'? As well as signalling a changing role or identity for educators in the context of a reflexive pedagogy, we are also seeing here the surfacing of issues relating to the power relations between educator and student. 
Power relations: A related observation centres around the change in power relations between us and the students. In adopting co-coaching as an intervention, we anticipated the empowerment this offered to students - clearly a positive thing - but I for one didn't really think about the potential for our 'authority' as experts to become less influential or that their increase in power necessitated that ours decrease. Even when students invite us back into their conversations, the role we are being asked to play is different. We are discussants rather than teachers. We have to be careful not to suggest theory as the 'solution' to whatever they are grappling with if this means undervaluing the act of dialoguing per se.

'Power relations' in this vignette are shown as insidious where asymmetry, presumably disrupted by co-coaching, is re-asserted but in reverse - participant 'increase in power' precipitates 'decrease' in educator power and influence. What was 'clearly a positive thing' in student/ participant empowerment has become an unanticipated diminishment for the educators. Note the 'even' in the comment that 'even when students invite us into their conversations' indicating this might not be a frequent or automatic recurrence, and the 'their' referring to student conversations not educator-student shared conversations. Here, identity undoing is inextricably associated with the movement of power as well as a change in role ('discussants rather than teachers') and the need to 'be careful' and avoid 'undervaluing' the very container of co-coaching that holds this learning philosophy. [First author] has not only

lost her identity as a 'master of theory' but also her role as 'teacher', her centrality in learning interactions and her surety ('being careful'). All these losses were unforeseen - 'Ifor one didn't really think' - prior to the experience of practice.

\section{Letter 2 - from [second author] to [first author]}

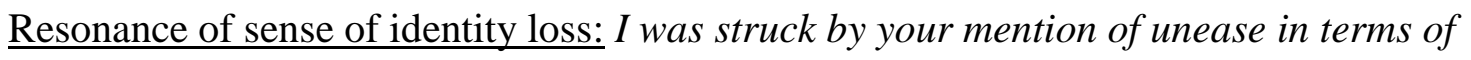
identity; the feeling of loss at not being seen as the 'sage on the stage'. Me too, but I felt it 
was not politically $O K$ to say so. Yet our role in this has confused [the students] and I think this is as a result of our identity issues (unconsciously) presented in front of them. At this moment I must confess, I recall hosting the third co-coaching session and found myself as a spare part in the event. I kept wandering around the groups trying to find a purposeful role. And the worst of it was the kindness of the students who sensitively linked me into their conversations.

[Second author] confirms and extends the feeling of 'unease' that the first author has put into words. It is notable that the second author felt that communicating their unease would 'not be politically correct'. It seems that critical educators/researchers feel discursive, communicative and pedagogical restraints on them to conform to their own ideologies and idealisations. [Second author] has a poignant narrative of being 'a spare part' reduced to 'wandering around the groups' in the hope of finding something 'purposeful' to do and being dependent on the 'kindness' of students to involve him. This suggests there is a visibility of educator identity undoing that is at least difficult and at worst humiliating. [Second author] seems convinced that such identity undoing being played out even 'unconsciously' has 'confused' students, although the students in the narrative, far from being confused, appear sensitive, generous and relationally adept about helping educators re-connect to their dialogues in a different way. The next vignette, however, speaks to the countering resistance to the disruption to traditional power relations which [second author] experiences as coming from students.

Resistance to the disrupted power relations: When I went around the room the students seemed so pleased, relieved that I was intervening and re-establishing the status quo. My overtures of offering some 'expert' input were enthusiastically grasped, in the sense that both they and I found our identities again and all was good in the world! 
This vignette serves to explain the framing of 'confusing' in the vignette which precedes it. It is a complex one to analyse because the educator and student interpretation might well be different here. In terms of the educator, the 're-establishing the status quo' recreates the students as 'pleased' and 'relieved'. The 'master of theory' identity is reestablished through 'expert input' and students revert to being enthusiastic recipients of such input. Relief is palpable where 'all was good in the world' at the reclaiming of traditional power, identity and role. The transfer of power, identity undoing and role diminishment seem fairly precarious and temporary in a space which confers on educators the institutional authority to retake those things at will.

\section{Letter 3 - from [first author] to [second author]}

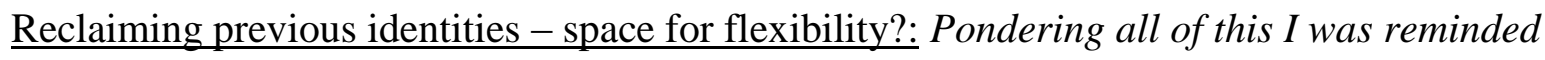
of when I worked in experiential learning. At that time, I would have a strong sense of credibility resting on how I worked rather than what I knew. I summarize those days by saying that I could facilitate a whole day's learning on one page of flipchart paper! My sense of identity as a good facilitator revolved around the process skills required to support learners in teasing out the lessons from their past experiences and using them to develop their future practice. When I entered academia this identity no longer felt valued. It felt as if my credibility and ability to add value now rested on being able to deliver theoretical content and - not confident enough to do this off the top of my head-my early teaching style dropped into 'death by Powerpoint'. It was a paradox of knowing more but feeling less knowledgeable. For me, working with a reflexive pedagogy may be about trying to come full circle and re-capture both the confidence and the competence of that earlier self, albeit in a very different (assessed and accredited) context. Yet so much else seems to be impacting on this potentially limiting such possibilities. 
Here [first author] recalls a time before she was an academic. Importantly, the prior experience she narrates here makes it clear that the 'unease' driving this sequence of letters is not from any lack of experience or skill at being a 'guide on the side'. [First author] reveals that once upon a time she could 'facilitate a whole day's learning on one page of flipchart paper' with enough 'process skills' to support, as opposed to leading, learning. Somewhat ironically, a previous case of identity unlearning occurred as she entered academia, where 'ability to add value' became correlated to 'death by Powerpoint'. One of the central paradoxes across these letters is directly articulated here, namely that 'knowing more' and 'feeling knowledgeable' are two entirely different things and don't necessarily go together. This episode of co-coaching and reflexive dialogue appears to have called upon the promise of a former experiential practitioner self to meet an academic expert self ( 'come full circle') and integrate 'confidence' and 'competence' in a new 'assessed and accredited' context. While this sounds a generative and aspirational outcome in one sense, it is held with relative pessimism, with other constraints 'potentially limiting such possibilities'.

Whilst we don't discover what students/participants learn as a result of co-coaching and reflexive dialogue (this being beyond the scope of this article), we do discover that, in this case at least, educators appear to live what they attempt to teach, which would indicate that reflexive pedagogies have the potential to disrupt educator power and identity as much or even more than that of students. If that could be the case then it seems crucial to further understand educator reflexivity and insight into their own power and identity dynamics. As [second author] comments in concluding the final letter, in order to reach any conclusions on the power and identity issues raised by the adoption of a reflexive pedagogy, it will be important to explore further the 'vulnerability' that educators experience when they 'switch from rational dialogue to the tensions associated with ... a pedagogy of the unknowable' (Hibbert and Cunliffe, 2015: 185). 


\section{Discussion}

The vignettes speak to complex, powerful and largely unforeseen disruption in terms of two critically informed, committed and experienced educators. These two educators 'consent [to], cope [with] and resist' (Kondo, 1990: 224) a range of power shifts in front of our very eyes with real demands placed on their resulting, often very visible, identity work. While in this section we do explore the challenges of such shifts and demands on educators, we do so with the intent of building capacity and tangible practices that will help others negotiate this 'pedagogy of the unknowable' with more tacit points of reference and a repertoire of identity practices than the two educators represented here were holding between them.

We understand power as a complex construct with which to work. Using Huxham and Vangen's (2005) frame, the notion of power by the educator need not just be considered as 'power over' students but also as 'power to' achieve educational aims. The educators in the vignettes appeared to initially miss the distinction between 'power over' and 'power to'. They seemed to experience both powers as bundled together and didn't consider until the final vignette that they could give up 'power over' but keep 'power to'. 'Power over' is most experienced perhaps as 'sage on the stage' but 'power to' seems more compatible with 'guide on the side'. [First author's] memory of experiential learning and facilitating 'a whole day's learning on one page of flipchart paper' would appear a marvellous example of claiming and holding the 'power to' support, stretch and make visible students' learning without relying on 'an implicit position of mastery' (Hibbert and Cunliffe, 2015: 186) that is the essence of 'power over'. 'Power to' needs to be understood as pedagogically sophisticated as in the power to frame questions, disrupt assumptions, prompt links to other experiences, draw in other stakeholder perspectives, tease out affective, embodied and aesthetic responses, and model being vulnerable and in doubt. The 'paradox of knowing more but feeling less knowledgeable' in this vignette needs to be recast in power terms as the difference between 
viewing knowledge as a source of power over students, as opposed to seeing the space between educator knowledge and student experience as the site of learning co-construction. If our two educators could have disentangled 'power over' and 'power to' they would have felt less bereft of value to students and the enterprise of learning.

This inability to disentangle different kinds of power points to more fundamental dynamics at a systems and institutional level which lock in a number of dominant identities at educator and student level. Both educators and students operate in a space which is far from power neutral and has already carved out lines of institutional, pedagogical and relational power. Malkki and Lindblom-Ylanne (2012) highlight barriers to changing pedagogy in higher education reflected in a desire to be seen as a professional (in the student-educator relationship) and to fall in line with institutional norms. Hedberg (2009) argues that these power relations are part of what the students are (quite literally) buying into when they enrol on a programme - they have an expectation that they will be 'taught by experts' and may feel short-changed if that doesn't occur. Nicholson and Carroll (2013: 1228) draw on the notion of normalizing judgment from Foucault's (1988) technologies of power to make sense of this set of expectations where 'rules and norms [are] to be followed, respected and preferred, as they represent the "optimum towards which one must move" (Foucault 1977: 183)'.

This concept of normalizing judgement explains what we could term the normalizing vignette where 'the students seemed so pleased, relieved that I was intervening and reestablishing the status quo'. It seems that both educators and students could have felt out of line with institutional norms, unmoored from a set of expectations that more than likely did include pedagogical control 'owned' by the educators, and relieved that rules and norms could revert to a more predictable and known learning terrain. We need to be careful, though, about viewing such a reversion as the reinstatement of a more natural order of things. Kondo's (1990) insights remind us that such a reversion is a moment of consenting and 
coping that can be undone by concurrent and subsequent moments of resisting. Following this line of thinking then, educators need to understand excursions into reflexive and critically orientated pedagogies as a set of see-sawing episodes which move fluidly and uncomfortably between traditional and disruptive learning relationships and activities. Educators who wish to move their learning interactions beyond traditional norms will need to build the capacity to map, track and name the experience of power dynamics with their students to build both a capacity and intentionality around consenting, coping and resisting.

Much of this capacity building will be affected by anxiety. We already know that educators can be unsettled by student responses to reflexive pedagogy and dialogue. Hibbert and Cunliffe (2015: 186) found that 'as students express their own emotions, confusion and perhaps resistance in the process of engagement, educators are likely [to] be faced with a set of class signals $[\ldots]$ that the educational process is not working'. However, such 'class signals' do not appear present in any of the vignettes as students appear to be working autonomously in their pairs, open about their different approach to theory, and confident about inviting educators in to their reflexive dialogues when they feel the need. Educators in this series of vignettes did not appear to be reading and responding to student emotion, confusion and resistance but to their own.

The educator relationship with theory appears to be at the heart of their anxiety and resisting. 'Driving with theory' appears to come from educators and as educators 'give up' pedagogical power then this driving is replaced by 'dipping into theory' and theory stops being 'the solution', meaning the student encounter with theory becomes 'superficial'. We need to pause here and understand theory as a crucial 'knowledge object' in the pedagogical enterprise (Miettinen and Virkkunen, 2005; Rheinberger, 1997). Knowledge objects can be understood as technical where they are treated as fixed, pre-defined, permanent and replicable, or epistemic where they are seen as relatively undefined, open-ended, historically 
situated and still experimental. In order to achieve new and novel practices objects need to be moved from a technical to epistemic frame which then allows for learning through a process of bricolage - characterised as 'improvising, imagining, playing and searching for new cultural resources' (Miettinen and Virkkunen, 2005: 451).

The vignette sequence, set within institutional norms, places emphasis on theory as largely technical where it appears to hold value as what it is (rather than what it enables), comes pre-formed and requiring acquisition rather than adaption, and is the end-game rather than one of a number of ingredients for meaningful learning. Ironically in the vignettes, it is the students who exhibit some degree of bricolage and who utilise theory in an epistemic way combining storytelling, practical experience, dialoguing and discussion. This distinction between technical and epistemic knowledge objects helps us understand the problem is not theory itself but how that theory is held and used. This is an identity question and the movement from using it in technical to epistemic ways can be viewed as an identity undoing question.

Identity undoing invites us to view the potential loss associated with theory in ways that go beyond simple notions of unlearning and relearning. The distance between being 'masters of theory' and 'a spare part' is after all a fairly large one and is characterised by fairly viscerally loaded words such as 'unease', 'insecure' and 'uncomfortable'. The original work on identity undoing (Nicholson and Carroll, 2013) implied, but didn’t specifically explore, that identity undoing might be quite different for educators as opposed to students. From their observational material it could be seen that while educators were committed to cocrafting a learning space with participants there was still marked asymmetry where the educators in essence held such a space - offering guidance, structure, advice and process facilitation - while students focused on learning how to learn in such a space. In now drawing attention to 'identity undoing' as experienced by educators in the context of a reflexive 
pedagogy, we would argue that there is an inherent relationality which occurs for both parties: a fluid interplay between the identities of educators and students, invoked through a process of claiming and granting (DeRue and Ashford, 2010) between the parties which allows the educator to fulfil different aspects of the learning process (e.g. supporting learning versus assessing assignments).

In our series of vignettes we gain a further sense of the complexities around educator undoing. Perhaps somewhat ironically these vignettes were based on an experience of engendering reflexive dialogue between students, yet no reflexive dialogue happened between educators and students. There was no space or scope for the educators to openly display their anxiety and doubt and the students couldn't assuage or reframe what needed to occur for the emergence of new educator roles. In short, no one was holding this learning space to support educator identity undoing. From the vignettes we see that if reflexive and critical pedagogies are to disrupt traditional roles and power relations, then it is not enough to offer new identities to students and not educators. A reflexive and critical space surely needs to be an intersubjective space where educators and students not just move in relation to each other but make that visible through artefacts, words and actions. 'Spare part' after all is not the direct opposite of 'master of theory' and there are a wealth of identity options in-between, one of which is presented in the final vignette where 'good facilitator' enters the picture based on 'how I work rather than what I know'. That might have actually been the identity students were 'sensitively' trying to link into their conversations. We suspect educators seeking to utilise a reflexive pedagogy have hugely underestimated the identity terrains implicit in much of this work and have even more underestimated the power of students to help hold such a space.

Without intersubjective and reflexive dialogue in the moment about the learning dynamics and identity work between educators and students, we appear to get sequences of 
resisting students and resisting educators who eventually run out of capacity to hold a reflexive learning space and eagerly retreat to a more traditional norm as they do in this vignette sequence. In a sense then there is a paradox with reflexive pedagogy: the greater the success in enabling reflexive dialogue between students, the greater the desire of the educator to intervene to limit the scope and impact of reflexivity in order to not become 'a spare part'. Such a paradox is supported by a raft of institutional and systemic norms and expectations. In light of this experience we suggest this has the effect of generating unconscious resistance to reflexive dialogue in both the students and educators. Educators eventually will resist the loss of value and expertise and students eventually will resist the loss of educator involvement and input. Both are required to undo significant aspects of learning and expert identities but, unlike for students, there is no-one to hold and support the identity undoing of educators unless they learn to do so better themselves and/or seek support and input from students.

Our take on pedagogic resistance draws on Mumby (2005: 37) who suggested that resistance is not a dysfunctional response to organisational control (Courpasson, Dany and Clegg, 2012) but rather is conscious resistance within unconscious control. In this way we suggest resistance and control become central mechanisms impacting on educators' ability to undertake reflexive pedagogy and more broadly critical management education. Set within the student-educator relationship, control reflects the normalizing expectations and the hierarchical observation, while the resistance is the conscious desire to protect the educators' identity as expert in control of the learning environment in lieu of there being other identity options for them. Some suggestions in relation to addressing this paradox present themselves in the insights arising from our testimonio inquiry, at least with regard to what educators might need to do differently in seeking to make the adoption of a reflexive pedagogy 'work' for both students and themselves. Three aspects appear relevant: first, a need to recognise a 
movement from institutionalised 'power over' to personal 'power to' as a significant component to reposition the educator role within a reflexive pedagogy; second, for educators to recognise the need to commit to their own reflexivity, and with their students, in the moment (rather than retrospectively as was the case here) in order to surface the intersubjective educator and student dialogue; and third to produce the 'holding environment' (Heifetz and Laurie, 1999: 127) required to process and mutually adjust to the changed identities and roles implicit in a reflexive context.

\section{Conclusion}

We would like to conclude by exploring the implications our contribution offers for advancing reflexive dialogue within LDPs. The potential for reflexive dialogue to have a significant role in enhancing leadership education has long been mooted (Cunliffe, 2002, 2008) and calls for a critical voice and critical pedagogic designs (Collinson and Tourish, 2015; Ford and Harding, 2007) are prominent. In the broadest principle we echo this however such calls do not speak to issues of educator power and identity, which our experiences have made salient. It is important to recognise the potential for significant discomfort in the student-educator relationship and for critical education to avoid 'the contradiction between a critically based curriculum and a methodology that reinforces authoritarian relationships' (Reynolds 1999: 550). Exploring in greater depth the apparent paradox that we have highlighted seems fundamental if reflexive dialogue in critical education is to realise its potential. Despite our desire and pursuance of critical management education to engage students in reflexive pedagogy we unintentionally reinforced the power asymmetries and hierarchical dependency within the educator-student relationship. Central to this paradox are issues of educator power and identity and in particular educator resistance to 'giving-up' power and 'letting go' of firmly held and valued identities, reinforced by apparent student collusion. Our contribution has been to highlight that without an awareness and 
understanding of this educator paradox the good intentions of critical management education may remain just that, good intentions.

Ways of addressing this paradox present themselves in the insights arising from our testimonio inquiry, at least with regard to what educators might need to do differently to make the adoption of a reflexive pedagogy 'work' for both students and themselves. Unpacking their own relationship with power, and developing the flexibility to move from 'power over' to 'power to' is likely to be a significant component in their ability to reposition themselves and their role. At the same time, they will need to commit to their own reflexivity, both between themselves and with their students, in the moment in order to surface the intersubjective educator and student dialogue and to produce the 'holding environment' required to process and mutually adjust to the changed identities and roles implicit in a reflexive context. This in turn, will be important in developing the skills and the confidence for educators and students to collectively experiment with a greater identity and pedagogical repertoire around the value and use of theory, such as to engage successfully with it as an 'epistemic frame' upon which to build affordances for mutual learning.

\section{References}

Alvesson, M and Willmott, H (2002) Identity regulation as organizational control: Producing the appropriate individual. Journal of Management Studies, 39(5): 619-44.

Baker, A and Kolb, DA (1993) Diversity, Learning and Good Conversation. In RR Sims and RF Dennehy (Eds.) Diversity and Differences in Organisations. Westport, CT: Quorum Books.

Beverley, J (2000) Testimonio, subalternity, and narrative authority. In N Denzin, and Y Lincoln (Eds.) Handbook of Qualitative Research (3rd edn). London: Sage, pp. 555-565. 
Boyatzis, RE (1998) Transforming qualitative information: Thematic analysis and code development. Thousand Oaks, CA: Sage.

Brown, AD (2001) Organization studies and identity: towards a research agenda. Human Relations, 54: 113-121.

Brown, A and Lewis, M (2011). Identities, disciplines and routines. Organization Studies, 32(7): 871-895.

Carden, LL and Callahan, JL (2007) Creating leaders or loyalists? Conflicting identities in a leadership development programme. Human Resource Development International, 10: 169186.

Carroll, B and Levy, L (2010) Leadership development as identity construction. Management Communication Quarterly, 24: 211-231.

Carroll, B and Nicholson, H (2014) Resistance and struggle in leadership development. Human Relations, 67(11): 1413-142.

Clandinin, DJ and Connelly, FM (2000) Narrative inquiry: Experience and story in qualitative research. San Francisco: Jossey-Bass.

Collinson, DL (2003) Identities and insecurities: Selves at work. Organization, 10(3): $527-$ 547.

Collinson, DL and Tourish, D (2015) Teaching leadership critically: New directions for leadership pedagogy. Academy of Management Learning and Education, 14(4): 576-594.

Connelly, FM and Clandinin, DJ (1990) Stories of experience and narrative inquiry. Educational Researcher, 19(5): 2-14.

Courpasson, D, Dany F and Clegg S. (2012) Resisters at work: Generating productive resistance in the workplace. Organization Science, 23(3): 801-819.

Cunliffe, A (2002) 'Reflexive Dialogical Practice in Management Learning', Management Learning, 33(1): 35-61. 
Cunliffe, A (2008) Orientations to social constructionism: Relationally responsive social constructionism and its implications for knowledge. Management Learning 39(2): 123-139.

Denzin, NK and Lincoln, YS (2000) Introduction: The discipline and practice of qualitative research. In NK Denzin, and YS Lincoln (Eds.), Handbook of qualitative research ( $2^{\text {nd }}$ ed). Thousand Oaks, CA: Sage, pp.1-28.

DeRue, DS and Ashford, SJ (2010) Who will lead and who will follow? A social process of leadership identity construction in organizations. Academy of Management Review, 35: 627647.

Ellsworth, E (1989) Why doesn't this feel empowering? Working through the repressive myths of critical pedagogy. Harvard Educational Review, 59: 297-324.

Fereday, J and Muir-Cochrane, E (2006). Demonstrating rigor using thematic analysis: A hybrid approach of inductive and deductive coding and theme development. International Journal of Qualitative Methods, 5(1): 80-92.

Ford, J (2006) Discourses of leadership: Gender, identity and contradiction in a UK public sector. Leadership, 2(1): 77-99.

Ford, J, Harding, N and Learmonth, M (2010) Who is it That Would Make Business Schools More Critical? Critical Reflections on Critical Management Studies. British Journal of Management, 21, s71-s81.

Ford, J and Harding, N (2007) Move over management: We are all leaders now. Management Learning, 38(5): 475-493.

Foucault, M (1977) Discipline and punishment. London: Allen Lane.

Foucault, M (1988) Technologies of the self. In LH Martin, G Gutman and PH Hutton (Eds). Technologies of the self: A seminar with Michael Foucault. London: Tavistock, pp. 16-49. 
Frank, A (2005) What is dialogical research and why should we do it? Qualitative Health Research, 15(7): 964-974.

Fulop, L (2002) Practising what you preach: Critical management studies and its teaching. Organization, 9: 428-436.

Gagnon, S (2008) Compelling identity: Selves and insecurities in global, corporate management development. Management Learning, 39: 375-391.

Gagnon, S and Collinson, D (2014) Rethinking global leadership development programmes: the interrelated significance of power, context and identity. Organization Studies, 35(5): 645-67.

Garfinkel, H (1967) Studies in Ethnomethodology. Malden: Polity Press.

Hawkins, B and Edwards, G (2015) Managing the monsters of doubt: Liminality, threshold concepts and leadership learning. Management Learning, 46(1): 24-43.

Hedberg, P (2009) Learning through reflective classroom practice: Applications to educate the reflective manager. Journal of management Education, 33: 10-36.

Heifetz, RA and Laurie, DL (1999) The work of leadership. Harvard Business Review, January-February, 124-134.

Hibbert, P (2013) Approaching reflexivity through reflection: Issues for critical management education. Journal of Management Education, 37(6): 803-827.

Hibbert, P and Cunliffe, A (2015) Responsible management: Engaging moral reflexive practice through threshold concepts. Journal of Business Ethics, 127: 177-188.

Huxham, C and Vangen, S (2005) Managing to Collaborate. London: Routledge. 
Kempster, S and Iszatt-White, M (2013) Towards co-constructed coaching: Exploring the integration of coaching and co-constructed autoethnography in leadership development. Management Learning, 44(4): 319-336.

Kermode, F (1981) Secrets and narrative sequence. In WJT Mitchell (Ed.) On narrative. Chicago, IL: University of Chicago Press.

Kondo DK (1990) Crafting Selves: Power, Gender, and Discourses of Identity in a Japanese Workplace. Chicago, IL: University of Chicago Press.

Malkki, K and Lindblom-Ylanne, S (2012) From reflection to action? Barriers and bridges between higher education teachers' thoughts and actions. Studies in Higher Education, 37: 33-50.

McAdams, DP and Cox, KS (2010) Self and identity across life span. The handbook of lifespan development. London: John Wiley \& Sons.

Miettinen R and Virkkunen J (2005) Epistemic Objects, Artefacts and Organizational Change. Organization, 12(3): 437-456.

Mumby, D (2005) Theorizing resistance in organization studies: A dialectical approach. Management Communication Quarterly, 19(1): 19-44.

Nicholson, H and Carroll, B (2013) Identity undoing and power relations in leadership development. Human Relations, 66(9): 1225-1248.

Petriglieri, JL (2011) Under threat: Responses to and consequences from threats to individuals' identities. Academy of Management Review, 36(4): 641-662 Reynolds, M (1999) Critical reflections and management education: Rehabilitating less hierarchical approaches. Journal of Management Education, 23(5): 537-553. 
Rheinberger, H-J (1997) Toward a History of Epistemic Things: Synthesizing Proteins in the Test Tube. Stanford: Stanford University Press.

Riach, K (2009) Exploring participant-centred reflexivity in the research interview. Sociology, 43(2): 356-370.

Rice, PL and Ezzy, D (1999) Qualitative research methods, a health focus. Melbourne: Oxford University Press.

Richardson, L (2000) Writing: A method of inquiry. In N. Denzin, and Y. Lincoln (Eds) Handbook of Qualitative Research (2nd ed). London: Sage, pp. 923-48.

Tatli, A (2012) On the Power and Poverty of Critical (Self) Reflection in Critical Management Studies: A Comment on Ford, Harding and Learmonth. British Journal of Management, 23(1): 22-30.

Thomas, R (2009) Critical management studies on identity: Mapping the terrain. In M Alvesson, T Bridgman, H Willmott, (Eds). The Oxford Handbook of Critical Management Studies. Oxford: Oxford University Press, pp. 166-186.

Wittgenstein, L (1953) Philosophical Investigations. Oxford: Blackwell. 